\title{
Research on Teaching Reform of Programming Courses Based on Large Class Flipped Classroom
}

\author{
Zhuo Li ${ }^{1, a}$ and Qi-xian Geng ${ }^{2, b^{*}}$ \\ ${ }^{1}$ College of Computer Science and Technology, Beihua University, Jilin, China \\ ${ }^{2}$ College of Mechanical Engineering, Beihua University, Jilin, China \\ a honeyton@126.com, b gengqixian@163.com
}

Keywords: flipped classroom; programming courses; large class system teaching; reform research.

\begin{abstract}
Facing the existing problems in the traditional teaching form in large classes of program courses teaching, the "Internet plus" technology and flipped classroom teaching mode are combined together. Aiming at the difficulties and key problems in large class flipped classroom teaching, flipped classroom teaching design mode based on "Internet plus" concept in large classes is put forward. It provides a new idea for the implementation of flipped classroom in programming courses of large class, and can provide reference for improving the quality of large class teaching in ordinary universities.
\end{abstract}

\section{Introduction}

Program design course is the core course of computer science and technology, software engineering and other professional, and closely related to various disciplines of the computer. Students' learning of programming courses will lay a solid foundation for the study of other courses in computer science and computer related work. Due to the content of the course is more, the concept is abstract, and has strong theoretical and practical, many students feel difficult to understand and master, unable to form a systematic understanding of the knowledge. In addition, more than $85 \%$ of the teaching forms in Chinese universities are large classes; traditional teaching methods have shortcomings such as single teaching method, low teaching efficiency and weak teaching pertinence, which make programming courses, become the course of difficult to learn, understand and teach in the heart of teachers and students [1]. Therefore, it is necessary to reform the traditional teaching mode. With the rise of new flipped classroom teaching mode, and the integration and application of multimedia technology and the "Internet plus" in the field of education, provides new ideas and new ways to solve the problem to us. Flipped classroom teaching reform which based on the concept of "Internet plus", is effective for solving the problems such as the large class teaching mode of programming course is unitary, students' learning enthusiasm is not high, and lack of interaction between teachers and students etc [2].

\section{The problems existing in the traditional teaching form in the programming course of large class system}

The traditional teaching is teacher centered in the classroom, teachers focus on the explanation and teaching of knowledge, students are passive recipients of knowledge; it is difficult to achieve the internalization of knowledge [3]. Especially for programming courses, because of the shortage of teachers, often take large class system teaching. Due to the large class size, the number of students, and the classroom is too large, results in the problem of difficult to effectively control classroom is particularly prominent. For example, the interaction between teachers and students in the large class teaching process is insufficient, and the students cannot get help and answer from the teacher in time. Due to the large classrooms, the number of classes, resulting in class attendance is not optimistic; classroom discipline is difficult to control, it is a common headache for students to 
watch mobile phones in class, the student will wander and think of can't see PPT clearly as an excuse. Why does the traditional teaching form have such problems in the programming course of large class system?

From the point of view of students, either the basic knowledge is weak, understanding and thinking ability is limited, cannot keep up the progress of classroom teaching, to give up; either the lack of goals and motivation, do not want to learn; some students lack the ability of self-management, self-control is poor, cannot keep on learning. From the teacher's point of view, either the teaching content is boring, cannot keep pace with the times; or the teaching form is dull and single, no attraction, resulting in students lack of interest in learning. Therefore, the "cramming" teaching mode in the traditional teaching is no longer applicable to the new generation of college students growing up in the Internet era. We cannot stand still, we must use new teaching idea and teaching form to adapt to the development needs of the times, to create a lively and vivid classroom teaching, improve students' learning interest and learning ability.

\section{Large class flipped classroom teaching design based on the "Internet plus" concept}

The flipped classroom teaching mode has attracted much attention in the education circle currently [4], it turn over the traditional classroom teaching structure, turn from teach first and learn later to learn first and teach later, flip from teacher centered to the students as the center, and can efficiently use the limited teaching time, achieve a better teaching effect. In recent years, with the development of the "Internet plus" concept, the Internet has a profound impact on the teaching ecology and the change of classroom structure [5]. For example, the teaching reform based on MOOC and SPOC network platform is more and more, here, MOOC refers to the network open courses related to the course, is the learning areas open to the society; while SPOC refers to the private learning area of the course class, which is the area for the teachers to manage the students and to manage their grades. We can combine SPOC with flipped classroom organically. On the one hand, using the advantages of SPOC network teaching platform, students are required to learn independently according to the knowledge designated by the teacher before class, and complete the online learning content on the SPOC; On the other hand, in the classroom, the flipped classroom teaching form is used to review, discuss, internalize and apply the knowledge points already previewed. In the process of two-way interaction between man and machine, between teachers and students, and between students and students, let students truly realize the deep integration of online and offline learning, That's what the meaning and the attraction are to implement the flipped classroom based on the "Internet plus" concept.

A. Difficulties and Key Points in Large Class Flipped Classroom Teaching

Now, the research on flipped classroom is mainly for small class teaching [6], how to apply flipped classroom to large class teaching is a key problem. The difficulties of large class flipped teaching are mainly reflected in the following aspects:

First of all: how to guide students to complete online learning before class is a difficult point in the implementation of flipped classroom teaching, and is also the key to the success of the flipped classroom teaching mode.

Second: how to design offline classroom teaching activities suitable for large class teaching to help students achieve deep learning. Especially in the course of classroom discussion, we will face the problems of how to group students and solve the problem of insufficient class hours.

Third: how to establish a set of perfect performance appraisal system to improve the quality of teaching in large class flipped classroom teaching.

B. Large Class Flipped Classroom Teaching Design Based on the "Internet Plus" Concept

The general design of large class flipped classroom teaching in programming courses is shown in figure 1 : 


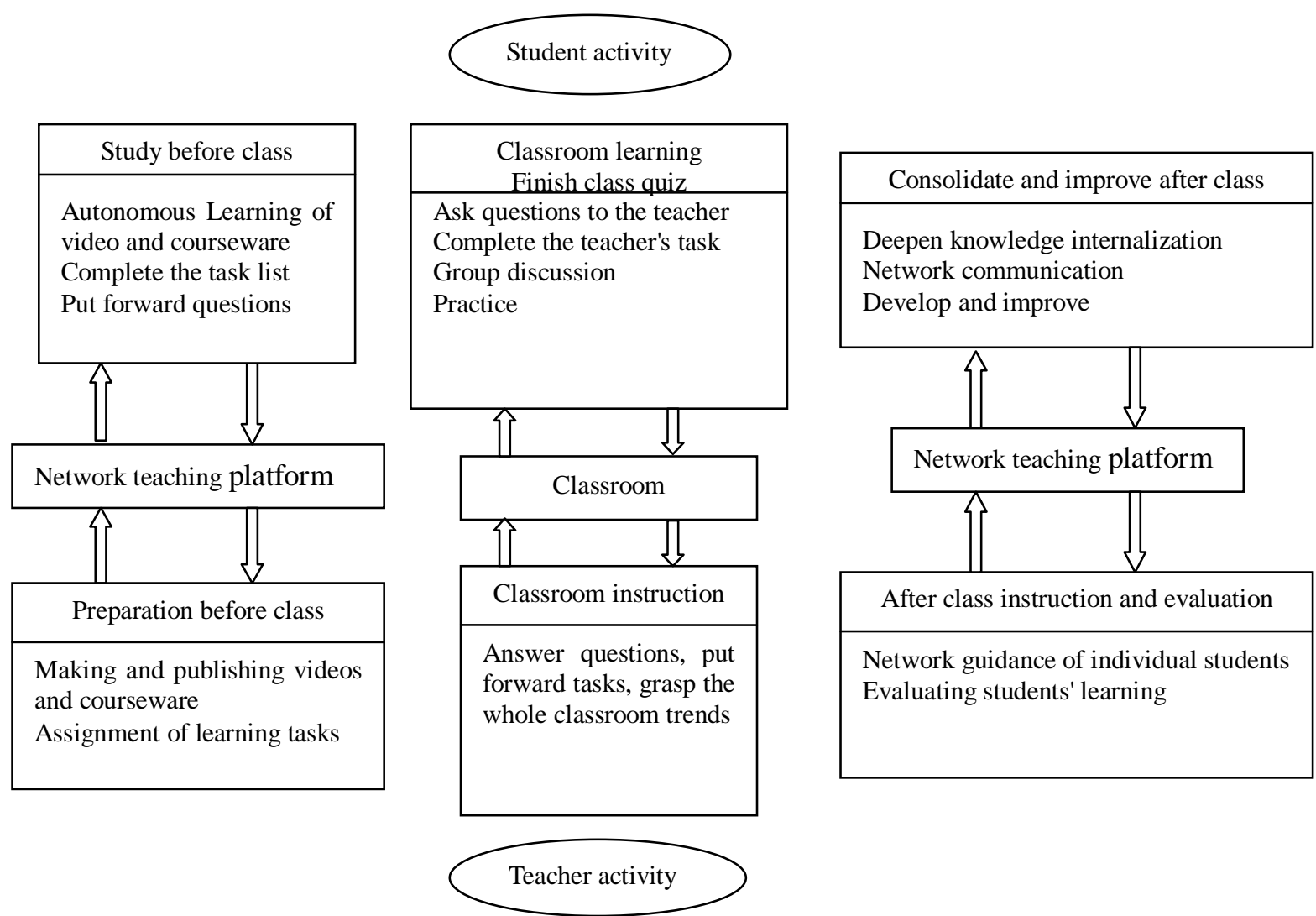

a. Preparation before Flipping

Fig.1. The overall design of teaching

Taking into account the students had no experience of flipping the classroom teaching form, in order to ensure the effectiveness of learning; we need to carry on the demand analysis before flipping the classroom. Demand analysis mainly includes two parts: one is student analysis, the other is teaching content analysis. Because students are the main body of flipped classroom teaching, through the analysis of students, we can understand the students' learning basis, learning habits and learning effect and other personalized differences, while taking into account the characteristics of professional, and as an important basis for selecting and producing teaching video. Content analysis is also a key point, because not all of the content is suitable for flipped classroom teaching, so we should choose the appropriate knowledge points according to the teaching syllabus for flipped teaching, usually should select the focus, difficulty and doubt of the learning content.

b. Teaching Process Design

Preparation and learning before class: First of all, based on previous needs analysis, the teacher selects or produces suitable learning videos, and strive to achieve short, focused learning videos. At the same time, through the study task list before class, we clearly pointed out the content of the study and designed some questions worth exploring, guiding students to think positively and stimulating students' interest in learning. Then upload these videos and preschool learning tasks to the network teaching platform, to download and learning independently by students. Students watch videos according to the learning task list, and study according to their own time and learning habits. If there is doubt in the study, teachers can communicate with each other online. In this process, we will encounter the first difficult point mentioned above. How to guide students to online teaching platform to complete online learning before class? And in order to solve this problem, the measure we take is to put the evaluation standard forward, that is, in the first class, give students a clear explanation of the examination method of online self-study effect, for example by class quizzes, 3 minutes quick questions and answers to evaluate the effect of students' self learning. Through this assessment and evaluation mechanism, urge students to self-study before class. If the students do not teach themselves before class, they should be responsible for their behavior through the punishment mechanism. At the same time, teachers should supervise students' learning process, 
evaluate students' learning effect and communicate with students timely through the network teaching platform, to avoid students' laziness and procrastination which leads to the fact that students cannot complete the task before class and the flipped classroom cannot be implemented.

Classroom teaching activities: On the basis of guiding students to complete the pre class learning on the network teaching platform, we must cooperate with the various forms, rich and interesting, and suitable for large class teaching offline class teaching activities to help students achieve deep learning. Here we are using the three activities which are test, speaking and practice. "Test" is to test students' self-study before class by using quizzes and 3 minutes quick questions and answers. Through the "test" link, one can effectively motivate students to learn carefully before class, on the other hand can help teachers to understand students' learning and self-study before class, quiz questions we use are not random, but can cover all the students in the class, so that all students are involved. Spend less time doing more, more suitable for large class flipped classroom. "Speaking" link is based on the students' feedback in the preparation stage and the common problems found in the quizzes, and the teacher makes a specific explanation. In addition, we can also analyze the problems extending and expanding from the test to the depth. In this process, students can be grouped into groups to discuss, contact and summarize the key and difficult content, make students form systematic cognition and complete the internalization of knowledge. For some problems and learning content, group discussion mode is more conducive to students' multi angle and comprehensive thinking, and the ultimately formation of pluralism and deep thinking of the problem."Practice" link is aimed at the characteristics of programming courses, teachers and students carry on the spot programming to some learning content in the classroom. In the process of spot programming and discussion, the establishment, verification and testing of the problem solution are formed; let students realize the unity of "learn to do" and "learn by doing". In the classroom teaching activities, we will face the second difficulties mentioned above: "How to group students and solve the problem of insufficient class hours during the class discussion process?"Here, we use the method of "Equilibrium between groups" and "Stagger inside the group" to divide students into groups, that is to say, about 5 students in each group, their learning basis, academic performance and practical ability is high and low difference and strong and weak distinction, and for the 12 discussion groups, the comprehensive ability of each discussion group is relatively balanced, so that the activity and participation of group discussion can be guaranteed. For class hours are not enough, we have two kinds of solutions. The first is to let the students prepared, that teachers should layout learning tasks before class, give students sufficient time to prepare and think. This can not only save the class interaction time, also can let students who are well prepared to be more power and more confident to participate in class activities, and the more confident, the more willing to prepare before class, thus forming a virtuous circle. Second is by the use of the experimental class hours as a supplement and extension for teaching class hours. Because of the programming courses, usually with experimental courses, the part of group discussion in class teaching and the content of "practice" are arranged in the experimental class, so as to solve the problem of insufficient classroom teaching hours.

Summary, improvement and evaluation after class: after class, students sum up what they have learned before class and in class activities, and according to the problems raised by teachers in the discussion area of network teaching platform, to guide to complete the development and improvement of knowledge, in this process, teachers and students can make further communication through the network teaching platform, teachers can give students personalized guidance and help. Finally, it is also the most critical step, must evaluate the performance of students. In order to improve the teaching quality, we must set up a perfect performance appraisal system by adopting the flipped classroom teaching mode. The flipped classroom teaching mode pays more attention to the preparation before class and the class performance, so the two factors should be taken into account in the assessment of the students, an evaluation system with quantifiable indicators should be established, so as to give an objective and fair evaluation of students' learning process and results. Because the preparation before class is mainly online completion in the network teaching platform, 
and classroom performance is done offline, therefore, our evaluation can be divided into two parts: online evaluation and offline evaluation. Each of these two parts accounted for $50 \%$ of the total score. Among them, online evaluation includes students' online learning before class, online interactive activity and completion of the study task list before class; and offline evaluation includes the completion of classroom tests, the performance of group discussions and the performance and completion of classroom practice.

\section{Conclusion}

Faced with the problems of large class programming courses teaching in the traditional teaching form, we need to meet the needs of social development with new teaching idea and teaching form, to create a lively and vivid classroom teaching, improve students' learning interest and learning ability. With the increasingly mature of "Internet plus" technology and the research on the flipped classroom teaching mode, we combine the two methods organically, aiming at the difficulties and key problems in large class flipped classroom teaching, put forward the large class flipped classroom teaching design mode based on "Internet plus" concept, it provides a new idea for the implementation of flipped classroom in programming class of large class system, and has certain practical significance and value. This teaching mode can not only be used in programming courses, but also can be used for reference in the application of large class flipped classroom in other courses.

\section{Acknowledgement}

The research work is supported by Educational Science “The 13th Five-Year” Planning Project of Jilin Province of China(Project "Research on Large Class Flipped Classroom Teaching Reform of Programming Courses under "Internet Plus" Background", No.GH170089).

\section{References}

[1] QIU Li-qing, CHEN Zhuo-yan, DING Chang-qing. Curriculum Reform of Program Design Based on Flipped Classroom Teaching Mode under The Background of Internet Plus [J]. Software Guide, 2016 15(12) 185-188.

[2] HU Shu-yu, WANG Zhuo. Research on The Application of Flipped Classroom in JAVA Programming Course [J]. China Management Informationization, 2017 20(9) 231-233.

[3] WU Ren-ying, WANG Tan. Flipped Classroom: Realistic Challenges and Coping Strategies for Teachers [J]. Educational Research, 2017 (2) 112-122.

[4] ZENG Ming-xing, LI Gui-ping. Construction of Deep Learning Field Based on MOOC and Flipped Classroom [J]. Research on Modern Distance Education , 2016 26(1) 41-49.

[5] LIU Kun-biao. Design of Flip Classroom Teaching Mode under "Internet +" [J]. Journal of Huanggang Polytechnic , 2017 19(1) 45-48.

[6] WU Yuan-hong, TAN Xiao-qiu, CHEN Rong-pin. Classroom Teaching Reform of University Computer Basis Based on "Shallow Flip of Large Class" [J]. Computer Education, 2017 (6) 140-142. 